\title{
Work Process Knowledge
}

\section{A Keyword of Modern Competence Development Focussed on the Chemical Industry}

\author{
Thomas Scheib \\ University of Dortmund, Lehrstuhl für Technik und ihre Didaktik I, Baroper Strasse 301, D- \\ 44227 Dortmund, Germany. \\ Email:scheib@ltdl.mb.uni-dortmund.de
}

\begin{abstract}
Modern production concepts like Total Quality Management, Lean production, Small factory unit or Business reengineering equate the human resource with the organisation and the technology. Therefore the knowledge of the workers about the execution and the optimisation of their working processes get an overriding importance. The so-called "Work process knowledge" becomes a new keyword in competence development. The following essay shows the difference as well as the relation between Work experience, Key competences and Work process knowledge. Based on that definition a model for the development of work process knowledge will be described. Finally difficulties and possible ways for the acquisition of working process knowledge are shown. These aspects are exemplarily applied to the work in the chemical industry.
\end{abstract}

Key words: Work process knowledge, Work experience, Expert groups, Cognitive apprenticeship

\section{INTRODUCTION}

Nowadays process optimisations are more likely to cause growth potential than technical developments. As a general rule, process optimisation is realised by the new organisation or reorganisation of working and business processes. Especially for the analysis and optimisation of the working processes, the experience and knowledge of the employees is of increasing importance.

With their work process knowledge, including experience and the knowledge of interactions and possible optimisations in the working process, 
employees make a substantial contribution to process and product innovations. The number of suggestions for improvement of employees can prove this. Therefore, the development of organisational competence and the promotion of the motivation to contribute it could become a decisive entrepreneurial aim in the next years. This also includes the creation of organisational options (knowledge, will, allowance).

\section{THE STRUCTURE OF WORK PROCESS KNOWLEDGE}

Work process knowledge is one of the keywords of modern competence development, but as well as the key competences this expression is not clearly defined. Literally, the work process knowledge is the essential knowledge to carry out a working process. In respect of integral acting, work process knowledge includes the knowledge of target setting, planning, execution, control and valuation of the working process. If the working process is described as a limited number of operations, which need to be carried out, the definition will be too narrow.

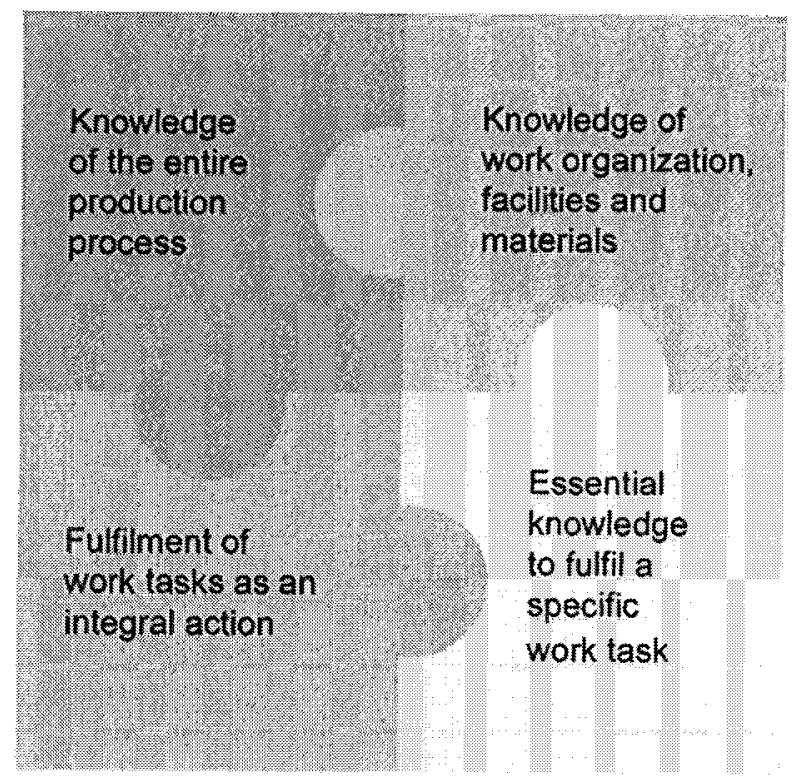

Figure 1. Definition of work process knowledge

Work process knowledge includes also the knowledge of work organisation, working capital and materials. It is especially important to be familiar 
with the equipment, its "snags", potential faults and the appropriate measures to solve the problems.

In chemical production processes it is also necessary to know the plant structure as well as the function of constituent elements. In every company this knowledge is different. Following the work process knowledge is rather depending on the company than on the profession.

Process orientation of modern production and management concepts like Total Quality Management, Lean Production or Business Reengineering further enhances work process knowledge.

The work process cannot be seen separately from previous and subsequent processes or the entire process. Work process knowledge embraces the knowledge of the connections of the production process itself and the embedding of the work process in the entire production process. Additionally, it includes the knowledge of the organisational structure and the processes prior or subsequent to each work or production process and how to implement and improve these.

To acquire work process knowledge, transparency of operational performance is absolutely essential. Transparency of the process structure refers to the separate phases of the process and their connections. Transparency of performance in the area of customer satisfaction, quality, time and costs is important to focus on weaknesses and optimisation potential in the process (KLING 2000).

Work process knowledge is of special importance, if the work process itself does not function properly. Besides the usual work routine, the question arises how malfunction and problems can be solved. Therefore work process knowledge includes the knowledge of how to prevent, realise and rectify malfunctions.

This aspect is especially considered in the continuous production processes of the chemical industry. The normal work there is increasingly characterised by data collection. Process control itself requires relatively less knowledge as long as the process works properly. Here the understanding of the production process and the facilities structure is just needed to a small extent.

In the case of malfunctions the required knowledge rises immensely to be able to minimise and to eliminate the interferences. The acquisition of knowledge of the plant structure becomes even more difficult due to the increasing level of abstraction of the process control (CAVESTRO 1989). 


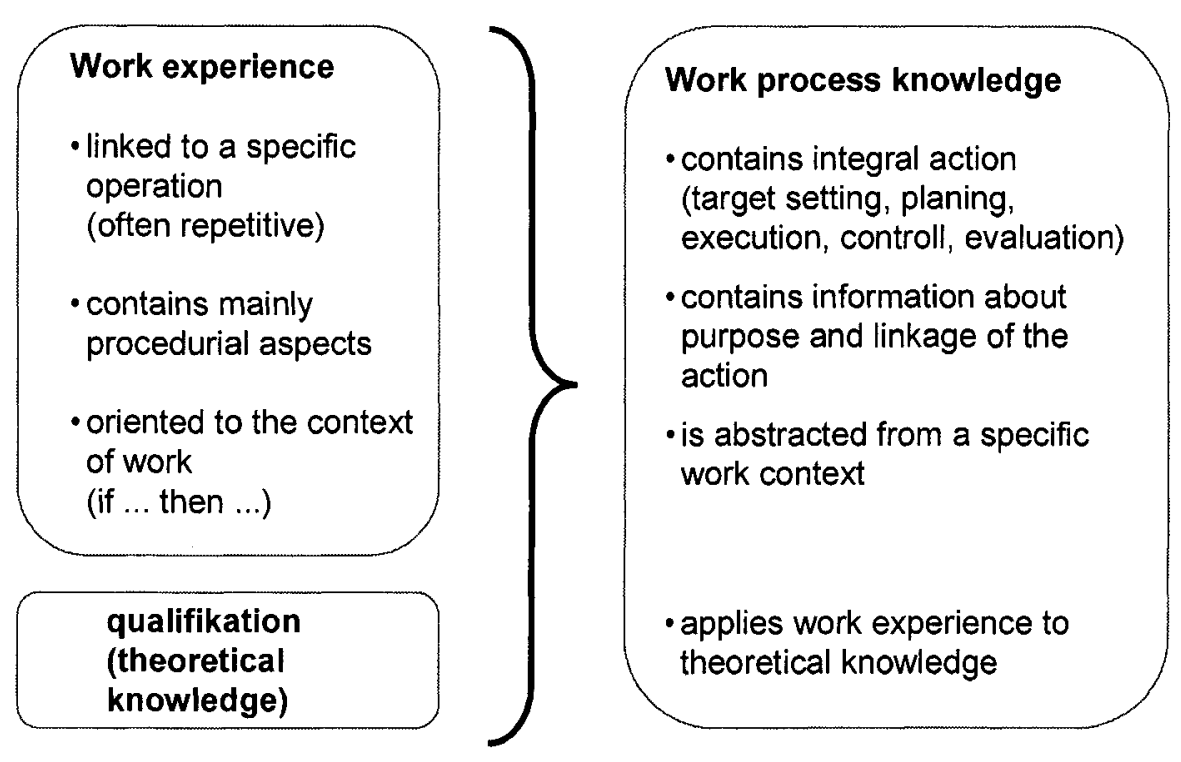

Figure 2. Work process knowledge and work experience

Work process knowledge can be described as a fusion of work experience and theoretical knowledge. Work experience always refers to a specific context that means a concrete work situation. Theoretical knowledge, which is mostly acquired through formal learning, is generally separated from concrete work situations and therefore hard to apply in such a work situation. So, on the one hand work process knowledge is the work experience, which can be reflected through theoretical knowledge. On the other hand, work process knowledge can be understood as specialised knowledge which is related to concrete work situations and enriched with appropriate knowledge.

The work in the process control centre in the chemical production is a good example to make it clear. A chemical worker in his final year of apprenticeship is not capable of running the production facilities yet, because work experience including special knowledge about the facilities is missing. The other way round the experienced mechanic in the maintenance, who knows the facilities in detail, lacks the specific chemical knowledge for the work in the process control centre. Theoretical knowledge and work experience are both necessary to control such a process.

The expression "Work process knowledge" could imply that it just deals with declarative knowledge. On one hand it is not only one-dimensionally limited to technical aspects. In the case of interferences fast material requirements planning and strategies for the solution of the problems have to be developed. In this way shortfall in production shall be minimised. This 
requires planning knowledge, which goes beyond the pure technical and has procedural parts. On the other hand declarative knowledge is not sufficient to eliminate malfunctions (solve problems). The employee often resorts to heuristic procedures of trial and error, hypothesis-forming and problem structuring and solving (CAVESTRO 1989), which contain also procedural knowledge. Further more work process knowledge generated out of work experience also includes contextual elements.

A correlation of work process knowledge only with problem solving holds the risk to include also methodical and social-communicative competences. In that way expanded, the expression "work process knowledge" should rather be replaced by the expression "work process competence" (SCHWERES 1998). But you have to take into account that it becomes difficult to distinguish this expression from the term "key competences". Therefore, the interpretation of "work process knowledge" just includes the knowledge itself. The knowledge certainly goes beyond declarative elements, but it separates clearly from competences to apply and acquire the knowledge (ability) and the willingness to use it.

So far, this text shows that work process knowledge includes a variety of aspects, e.g. operational or system-depending aspects. These aspects depend on the applied technical and the existing organisational structure. A change in these areas always involves a change in the needed work process knowledge and therefore requires an alteration of the definition of its content.

\section{THE ACQUISITION OF WORK PROCESS KNOWLEDGE}

Work process knowledge is largely gained in the working process itself. The reflection of practical experience and its connection with existing knowhow transforms it to work process knowledge (DERBOVEN 2002). In this way, work process knowledge develops from learning out of experience and from intentional learning. From knowledge out of experience and theoretical knowledge, knowledge of action arises. The difficulties of this connection can be found in the incoherent structure of the two learning methods. Generally, theoretical knowledge is gained outside a concrete working context.

In contradiction to that experience emerges in the concrete working process, which often crosses scientific fields. Reflection of experience through theoretical knowledge means the interaction of taking things out of context (de-contextualisation) of concrete working experience and the contextualisation of existing theoretical knowledge.

The acquisition of "new" work process knowledge is linked to new working situations. They develop from technical or organisational changes 
or out of problematical situations, e.g. interferences in the working processes.

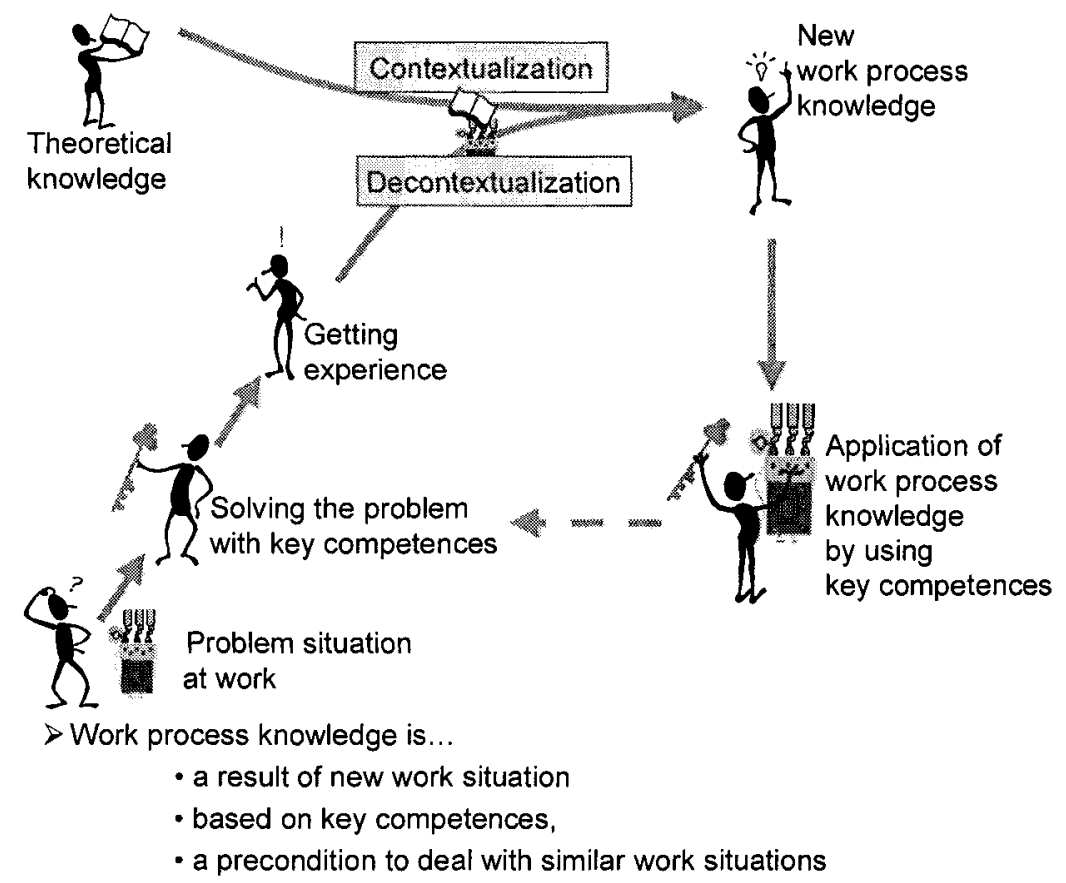

Figure 3. Development of work process knowledge

To cope with these situations work process knowledge and key competences like problem solving methods, the acquisition of information and the absorption of external experience (through cooperation and communication) have to be utilised. The process of solving problems creates work experience. To develop work process knowledge on this basis, work experience has to be substantiated with the help of theoretical knowledge (Decontextualisation). Simultaneously, theoretical knowledge has to be related to the concrete work situation (Contextualisation). Following, in respect to the application, theoretical knowledge is enriched and new structured. Work experience, resulting from the concrete work situation, is abstracted. To apply and to pass on the new acquired knowledge to similar work situations, key competences like the ability to communicate are necessary.

Enlarged work process knowledge is not only helpful in comparable work situations, but also changes and supports the process of solving problems in different situations. 
But the problem of the acquisition of work process knowledge lies in new or problematic work situations. In problematic situations, especially when the process is interfered, there is mostly no time for reflection and for the learning process to gain work process knowledge. But the knowledge, which is necessary to solve the problems, can only be developed in such situations. In the extensive automatic production of chemical products this phenomenon becomes very clear. If the production works properly, only less knowledge is necessary to handle the control room. The computer-aided production and schematic presentation reduce the required knowledge to a great extent. The complexity of the production process remains a secret to the operator. Exactly this aspect intensifies the problems, if there is interference in the process. The complexity of modern control systems, which normally makes work easier, causes additional difficulties here. On the one hand the operator has to be acquainted with the "additional" system and on the other hand he loses the direct contact to the facilities (vibrations, noise) and to the process. However, this contact is necessary to develop work process knowledge.

Consequently, computer-aided, automated, continuous production in the chemical industry complicates the acquisition of work process knowledge in three ways. Firstly, automation requires consolidated knowledge. Secondly, the automation "separates" the employee in the control room from the facilities and therefore takes away the possibility to develop an understanding for the system. Furthermore, the control system is capable of eliminating interferences on its own or has at least mechanisms to reduce interferences. Consequently, the control systems prevent some possible learning situations.

So there is an unresolved contradiction of the increased formalisation of work and the existence of breakdowns, unforeseen incidents and errors (CAVESTRO 1989). Remaining interferences are all the more complex and grave and therefore difficult to deal with.

\section{ADVANCEMENT OF WORK PROCESS KNOWLEDGE}

The advancement of work process knowledge is often associated with the key phrase "Learning in the working process". For example participation of the plant operators in the construction and the run-in of the plant is an ideal precondition to develop know-how of the plant structure (JÜRGENS 1990). Mostly, this ideal situation does not appear. Therefore experience has to be gathered through different ways. The lacking opportunities given by control units to perceive the process, make it more difficult to get this experience and to acquire work process knowledge. Beyond the tasks "Learning in the working process" is influenced by job design, job organisation, self-image 
and learning culture of the company as well as qualifications and motivation of the employees.

In modern production concepts, responsibility is delegated and self-control increased to enlarge the scope of the operating units to give them the opportunity to acquire knowledge on their own. Employees even demand this scope. An integral action, which is a precondition of the learning process, is also considered in the concepts (HACKER 1986). In addition, the social organisation of the working process (cooperation and coordination) has a supporting function for the acquisition of competences.

For the acquisition of work process knowledge the cooperation of the employees is relevant. Here the organisational form of working groups supports the acquisition of work process knowledge. Differences can be realised in the constellation of the groups. A group of "specialists" enlarges the spectrum of knowledge available in the group, but makes the exchange of knowledge more difficult, as the perspectives of the group members differ a lot.

The work structure principle of job rotation supports the development of work process knowledge in the group. With this principle special requirements are linked which go beyond the formally demanded competences in groups (JÜRGENS 1990).

For the development of new work process knowledge, the reflection and de-contextualisation of work experience as well as the possibility to relate theoretical knowledge to specific tasks is important.

Besides the above-mentioned prevailing conditions, employees have to be able to initiate self-learning processes. This requires the development of organisational and structural aids. Following, two examples will be described which support the acquisition of work process knowledge in an early phase of working life that is characterised by less work experience.

\subsection{Experience Circles or Cross-Training}

Experience circles or groups deliver a possibility to change knowledge to experience. Experience groups are based on the concept of quality circles. Quality circles are/were often used to discuss group-related, global working problems. Experience groups do not concentrate on the problem layer, but access to concrete solutions and working experience. In these groups, individual know-how and skills referring to a specific situation are transferred to colleagues. Experience of the group members overlaps and therefore broadens. It is also a step to transfer the specific experience to an abstract level. The other way round, it is also possible to relate theoretical knowledge to the experience. The essential work process knowledge is not only linked to an individual person, but to the whole work group. 
DAVENPORT (1993) pursuits a similar approach, which he describes as "Cross-Training". This means that colleagues teach each other according to the motto: "You teach me, and I teach you" (DAVENPORT 1993, p. 107). This principle can be transferred to the apprenticeship and therefore takes up the old approaches in the middle Ages. Young and inexperienced colleagues who have got a fundamental theoretical knowledge work together with experienced colleagues. Following, the experienced colleagues can support the young and the young colleagues can help the older ones to reflect upon their experience. Old-fashioned theoretical knowledge of older colleagues can be replenished and updated with the current specific knowledge of the younger colleagues. This concept can only be successful, if the relationship of the work group members is cooperative, free of prevailing prejudices and based on mutual confidence.

\subsection{Working and Business Process Orientated Apprenticeship}

Orientation at working and business processes in the apprenticeship aim at an enforced use of theoretical knowledge and skills in practical experience. The learning process itself focuses on the realisation of operational tasks. Here, the acquisition of theoretical knowledge is linked with precise working experience. Methodical and social competences become realistic. With the solution of these operational tasks professional competences (e.g. knowledge and skills) should be increased.

In English speaking countries a comparable and wide spread approach is the "Cognitive Apprenticeship". This approach follows the constructivism and includes four basic principles:

- authenticity of the task and the learning situation,

- practical and situated application,

- multiple contexts,

- social context.

A possible implementation of these approaches can be found in tangible tasks of operational projects for the trainee. Through these tasks, the learning process is orientated towards technical, organisational, and social conditions in modern work systems. Additionally, the trainee gets the opportunity to gain work experience - already during the apprenticeship. An example in the apprenticeship as a chemical worker is the immediate experience of the high complex facilities, which cannot be replaced by representations (for example by schematic representations in a simulation). Furthermore the integration of the work process in the total operational process and its organisation was of great interest for the trainees. 
Limits of working and business orientation can be found in the acquisition of work process knowledge in tangible problem situations. An interference cannot be planned. Problem situations are a challenge themselves, which make it difficult to involve trainees, but they can be trained with computer-based simulation programs. The concrete senso-motoric experience as described above, which is of specific importance in real cases, can be gained only partly and via media.

Further difficulties of application-orientated imparting principles can be found in the externalisation of cognitive processes and the accessibility of knowledge. Many aspects are kept on the level of work experience and cannot be transferred to similar work situations. All the more it is difficult to transfer these aspects to colleagues.

\section{CONCLUSION}

In my opinion, there is not the silver bullet to advance work process knowledge. For the advancement of work process knowledge the interaction of many factors is important. These factors relate on the one hand to the task and the work place. This includes for example complete action, sufficient Leeway for decision and design, permanent and appropriate challenges and problems as well as group-orientated organisational structures.

On the other hand these are factors, which relate to the employee. Besides the de-contextualisation of working experience in special situations and the contextualisation of theoretical knowledge, it is also of special interest to advance and motivate self-learning aptitude.

\section{REFERENCES}

CAVESTRO, William:

Automation, new technology and work content.

In: The transformation of work.

Eds.: WOOD, Stephen.

London, New York: Routledge, 1992.

DAVENPORT, Thomas H.:

Process innovation: Reengineering work through information technology.

Boston: Harvard Business School Press, 1993.

DERBOVEN, Wibke; DICK, Michael; WEHNER, Theo:

Die Transformation von Erfahrung und Wissen in Zirkeln.

In: Lernfeld: Arbeitsprozess.

Eds.: FISCHER, Martin; RAUNER, Felix.

Baden-Baden: Nomos Verlagsgesellschaft, 2002, pp. 369-392. 
DYBOWSKI, Gisela:

Berufliches Arbeitsprozesswissen.

In: Lernfeld: Arbeitsprozess.

Eds.: FISCHER, Martin; RAUNER, Felix.

Baden-Baden: Nomos Verlagsgesellschaft, 2002, pp. 355-368.

FISCHER, Martin:

Von der Arbeitserfahrung zum Arbeitsprozesswissen.

Opladen: Leske + Budrich, 2000.

HACKER, Winfried:

Arbeitspsychologie.

Bern, Stuttgart, Toronto: Huber, 1986.

JÜRGENS, Uwe:

Aktueller Stand von Produktionssystemen - ein globaler Überblick.

In: angewandte Arbeitswissenschaft,

Köln, (2003)176, pp. 25-36.

KLING, Jens:

Geschäftsprozessorientierte Personalentwicklung.

Wiesbaden: Gabler, 2000.

SCHWERES, Manfred:

Arbeitssystemwissen oder Arbeitsprozesswissen in der Berufsausbildung?

In: Die berufsbildende Schule,

Berlin, 50(1998)5, pp. 159-164. 